\title{
Seroprevalence of Dengue Viral Infection in Patients attending Tertiary Care Hospital, South Gujarat, India
}

\author{
Hitesh R. Ahir* and Hetal G. Vaghela \\ Department of Microbiology, GMERS Medical college, Gotri, Vadodara, India \\ *Corresponding author
}

\begin{tabular}{|c|c|}
\hline & A B S T R A C T \\
\hline $\begin{array}{l}\text { Ke y w or d s } \\
\text { Aedes } \\
\text { mosquitoes - } \\
\text { dengue - } \\
\text { DF/DHF - } \\
\end{array}$ & \multirow{3}{*}{$\begin{array}{l}\text { Dengue virus comes to group of family Flaviviridae, having four serotypes } \\
\text { which spread by the bite of infected Aedes mosquitoes. It causes a wide } \\
\text { variety of illness from mild asymptomatic illness to severe fatal dengue } \\
\text { haemorrhagic fever/dengue shock syndrome (DHF/DSS) as complications in } \\
\text { later stage of disease. In India, the first epidemic of clinical dengue-like } \\
\text { illness was recorded in Madras(now Chennai) in } 1780 \text { and the first } \\
\text { virologically proved epidemic of dengue fever (DF) occurred in Calcutta } \\
\text { (now Kolkata) and Eastern Coast of India in 1963-1964. }\end{array}$} \\
\hline Article Info & \\
\hline $\begin{array}{l}\text { Accepted: } \\
\text { 04 October } 2016 \\
\text { Available Online: } \\
10 \text { November } 2016\end{array}$ & \\
\hline
\end{tabular}

\section{Introduction}

Dengue is an acute viral infection with very serious complications. The word "dengue" is derivedfrom the SwahiliKa-dengapepo, meaning"cramp-like seizure". The first clinically recognizeddengue epidemics occurred almost simultaneously inAsia, Africa, and North America in the 1780s. The firstclinical case report dates from 1789 of 1780 epidemicin Philadelphia is by Benjamin Rush, who coined the term "break bone fever" because of the symptoms of myalgia and arthralgia. Dengue viruses (DV) belong to family Flaviviridae and there are four serotypes of the virusreferred to as DV-1, DV-2, DV-3 and DV-4. Itis transmitted mainly by Aedesaegypti mosquito.
Four main characteristicmanifestations of dengue illness are

(i)continuous high grade fever lasting 4-7 days;

(ii)haemorrhagic tendency asshown by a positive tourniquet test, petechiae orepistaxis;

(iii)thrombocytopoenia (platelet count $<1$ lac)

(iv)evidence of plasma leakagemanifested by haemoconcentration (an increase inhaematocrit $20 \%$ above average for age, sex andpopulation), pleural effusion and ascites, etc 


\section{History}

Dengue virus was isolated in Japanese people in 1943 by inoculation of serum of patients in suckling mice (Imura et al., 1944) andat Kolkata in 1944 from serum samples of US soldiers. The first epidemic of clinical denguelikeillnesswasrecordedinChennaiin 17 80 and the first virologically proved epidemic of DF in India occurred in Calcutta and Eastern Coast of India in 1963-1964 (Sabin, 1945). The first major epidemic of the DHF occurred in 1953-1954 in Philippines followed by a quick global spread of epidemics of DF/DHF (Sarkar $e t$ al., 1964; Chatterjee et al., 1965).

\section{Epidemiology of Dengue in India}

The situation of dengue in our country is reflected by the occurrence of major dengue outbreaks in India over last few years. However, reliable data are not available to assess the exact magnitude of the dengue in india. In 1996, the first major outbreak of dengue fever in occurred in Delhi where more than 10,000 cases and 400 deaths were reported (Sharma et al., 1998). Outbreaks and deaths have been reported from northern states of Haryana, Punjab and Uttar Pradesh; southern states of Andhra Pradesh, Tamil Nadu and Karnataka; western states of Gujarat and Rajasthan; and eastern state of West Bengal etc. In fact, the case fatality rate has been more than $1 \%$ during the last 10 years (World Health Organization, 2009).

The predominant serotype observed in 1996 was DEN-2, whereas all dengue serotypes were detected in 2003 outbreak in north India. Dengue outbreak in 2005 in Delhi was mainly due to DEN-3 serotype. The mortality observed in 1996 was far greater than the outbreak in 2003 and possibly can be explained by thedifference in the serotypes (DEN-2 is more virulent than DEN3) (Gupta et al., 2006; Dar et al., 2006; Gupta et al., 2005). It has also been observed that Aedes aegypti tends to be more susceptible to infection by DEN-2 virus of Southeast Asian genotype as compare to American genotype. These observations obviously have important epidemiological implications for Asian countries as the local vector has increased propensity to transmit dengue infection, especially DEN-2.

\section{Clinical Features}

$\mathrm{DF}$ is an acute viral disease manifesting with myalgias, headache, retro-orbital pain, vomiting, maculopapular rash, leucopenia and thrombocytopenia etc. DHF is characterized by four major clinical features: high fever, hemorrhagic phenomena, hepatomegaly and signs of impending circulatory failure (postural hypotension, resting tachycardia, sweating, shock etc). The typical laboratory manifestation of DHF is significant thrombocytopenia with concurrent hemoconcentration. The patients of DHF with excessive plasma loss resulting in shock are labeled as dengue shock syndrome (DSS).

The severity of disease in DHF/DSS depends on the quantity of plasma leakage, which is the major pathophysiological abnormality differentiating DF from DHF/DSS. The plasma leakage is due to generalized vasculopathy (hemoconcentration, hypo proteinemia and/or serous effusion) caused by dengue virus. In fact, it is very important to know that platelet count is not predictive of hemorrhage in DHF/DSS $(11,12)$. The risk factors of severe hemorrhage and subsequent mortality are duration of shock and low-normal hematocrit at the time of shock (Gupta et al., 2005). However, the 
clinician must take into account the potential effect of pre-existing anemia, severe hemorrhage and dehydration while interpreting hematocrit as a manifestation of DHF. DHF/DSS are potentially fatal conditions if managed inappropriately. The disease may present as acute acalculous cholecystitis, hepatitis, edematous gall bladder wall on ultrasonography, serositis involving pleural and abdominal cavity, fulminant hepatic failure, splenic rupture, acute renal failure orneurological manifestations including intracranial bleeding, seizures and myelitis (Dash et al., 2005; Armstrong, 2003). At times, acute acalculous cholecystitis dueto DHF may lead to unwarranted surgical intervention with catastrophic bleeding consequences due to thrombocytopenia.

\section{Methods}

In central service laboratory, We have collected serum samples of the suspected patients of Dengue then after we are performing rapid Dengue IgM test and we have confirmed all the samples by Dengue Ig M ELISA or NS1 antigen ELISA according to onset of illness.

\section{Results and Discussion}

We have received a total number 1146 serum sample of suspected Dengue patients at GMERS general Hospital, Valsad during the period from June 2014 to June 2015. Out of 1146 serum samples, 148 serum samples were detected Dengue Positive by ELISA methods.

Appropriate diagnosis of Dengue viral infection is routinely done by demonstration of anti Dengue IgM antibodies or by NS-1 antigen in patients' serum depending upon onset of illness using ELISA kits (prepared by National Institute of Virology, Pune) and commercial kits (Armstrong, 2003).

Total number of Dengue NS1 Antigen Positive were 39 out of 148 serum samples and Total number of Dengue IgM Antibody Positive were 109 out of 148 serum samples.

Table.1 Showing Monthwise list of Dengue cases.

\begin{tabular}{|l|c|l|}
\hline Month and Year & $\begin{array}{l}\text { Total Number of serum } \\
\text { samples for suspected } \\
\text { Dengue }\end{array}$ & $\begin{array}{l}\text { Total number of Dengue } \\
\text { Positive }\end{array}$ \\
\hline June 2014 & 22 & 02 \\
\hline July 2014 & 64 & 12 \\
\hline August 2014 & 241 & 26 \\
\hline September 2014 & 354 & 45 \\
\hline October 2014 & 107 & 17 \\
\hline November 2014 & 262 & 38 \\
\hline December 2014 & 38 & 05 \\
\hline January 2015 & 00 & 00 \\
\hline February 2015 & 00 & 00 \\
\hline March 2015 & 02 & 00 \\
\hline April 2015 & 15 & 00 \\
\hline May 2015 & 27 & 02 \\
\hline June 2015 & 14 & 01 \\
\hline Total & 1146 & 148 \\
\hline
\end{tabular}


Table.2 Showing Dengue Positive cases by different test

\begin{tabular}{|c|c|c|}
\hline Total Positive Dengue Test & Dengue NS1 ELISA & Dengue IG M ELISA \\
\hline 148 & 39 & 109 \\
\hline
\end{tabular}

In our study, Prevalence of Dengue in Valsad District of South Gujarat were 12.91\%. Prevalence were higher during monsoon season which is due higher rate of mosquito breeding during monsoon. In our study, Prevalence of Dengue infection was more during the month of August, September and November.

Dengue cases were tested positive by two different methods NS1 Dengue ELISA and Ig M Dengue ELISA in which 109 serum samples were tested positive by Ig $\mathrm{M}$ Dengue ELISA and 39 serum samples were tested Positive by NS1 Dengue ELISA .

\section{Prevention}

Nowadays, dengue vaccine is still under trial. Briefly, dengue virus survival depends on three factors: mosquito, water and environmental temperature. Environmental temperature is beyond our control due to global warming. However, we can surely anticipate and tackle the water and mosquito combination on which dengue virus survives in the period August-November every year. The Strategy for the reduction in transmission of dengue is the role of community participation and municipal machinery in vector control. Aedesaegyptifeeds during the day, rests indoors and lays its eggs in artificial water containers.

Vector control includes simple measures like eliminating larval habitats, using insect repellents/indoor space-spray insecticides/outdoor fogging and mosquito nets for children while sleeping. It also include to remove collected water from tyres, coolers and various pits from the land.
In India, we require a national 'awakening' program about the sanitation and garbage disposal which result in many infectious diseases like Dengue, malaria, Chikungunya, hepatitis, diarrhea.

In conclusion, dengue disease continues to occur in newer areas, newer populations and is increasing in magnitude, epidemic after epidemic also according to seasonal variation as in our study Dengue is more prevalent in monsoon. Every aspect of dengue viral infection continues to be a challenge.

\section{References}

Armstrong, P.M., Rico-Hesse, R. 2003. Efficiency of dengue serotype 2 virus strains to infect and disseminate in Aedesaegypti. Am. J. Trop. Med. Hyg., 68: 539-44.

Carey, D.E., Myers, R.M., Reuben, R., Rodrigues, F.M. 1966. Studies on dengue in Vellore, South India. Am. J. Trop. Med. Hyg., 15: 580-7.

Chakravarti, A., Kumar, A., Malik, S. 2011. Detection of dengue infection by combining the use of an NS1 antigen based assay with antibody detection. Southeast Asian J. Trop. Med. Public Health, 42: 297-302.

Chatterjee, S.N., Chakravarti, S.K., Mitra, A.C., Sarkar, J.K. 1965. Virological investigation of cases with neurological complications during the outbreak of haemorrhagic fever in Calcutta. J. Indian Med. Assoc., 45: 314-6.

Dar, L., Gupta, E., Narnag, P., Broor, S. 2003. Cocirculation of dengue 
serotypes, Delhi, India, Emerg. Infect. Dis., 12: 352-3.

Dash, P.K., Saxena, P., Abhyankar, A., Bhargava, R., Jana, A.M. 2005. Emergence of dengue virus type- 3 in northern India, Southeast Asian J. Trop. Med. Public Health, 36: 370-7.

Gupta, E., Dar, L., Kapoor, G., Broor, S. 2006. The changing epidemiology of dengue in Delhi, India, Virol. J., 3: 92.

Gupta, E., Dar, L., Narang, P., Srivastava, V.K., Broor, S. 2005. Serodiagnosis of dengue during an outbreak at a tertiary care hospital in Delhi, Indian J. Med. Res., 121: 36-8.

Hati, A.K. 2006. Studies on dengue and dengue hemorrhagic fever in West Bengal State, India. J. Commun. Dis., 38: 124-9.

Imura, K.R., Hotta, S. 1944. Studies on dengue fever (IV) on inoculation of dengue virus into mice. Nippon Igaku, 3379: 629-33

Sabin, A.B., Schlesinger, M.C. 1945. Production of immunity to dengue 4. with virus modified by propagation in mice. Sci., 101: 640-2.

Sarkar, J.K., Chatterjee, S.N., Chakravarty, S.K. 1964. Haemorrhagic 5. fever in Calcutta: some epidemiological observations. Indian J. Med. Res., 52: 651-9.

Sharma, S., Sharma, S.K., Mohan, A., Wadhwa, J., Dar, L., Thulkar, S., et al. 1998. Clinical profile of dengue haemorrhagic fever in adults during 1996-outbreak in Delhi, India, Dengue Bull., 22: 20-27 (WHO-SEARO).

Vajpayee, M., Mohankumar, K., Wali, J.P., Dar, L., Seth, P., Broor, S. 1999. Dengue virus infection during postepidemic period in Delhi, India. Southeast Asian J. Trop. Med. Public Health, 507-10.

World Health Organization. Regional office for South-East Asia [homepage on Internet]. New Delhi: Trend of Dengue cases and CFR in SEAR Countries. c2009 [cited 2009 October 23]. Available from: http:// www.searo.who.int/en/Section10/Secti on332/Section2277.htm

\section{How to cite this article:}

Hitesh R. Ahir and Hetal G. Vaghela. 2016. Seroprevalence of Dengue Viral Infection in Patients attending Tertiary Care Hospital, South Gujarat, India. Int.J.Curr.Microbiol.App.Sci. 5(11): 92-96. doi: http://dx.doi.org/10.20546/ijcmas.2016.511.010 